\section{Esophageal insertion of polyflex stents without fluoroscopy in peptic strictures}

I read with great interest the article by Dormann et al. on the use of a recently marketed self-expanding plastic stent (Polyflex, Rüsch, Germany) to alleviate dysphagia caused by esophageal carcinoma [1]. As the authors expected, the use of this type of stent has now extended to include benign strictures [2], and the stent is also increasingly being used to seal perforations and anastomotic leaks in the esophagus [3]. The Polyflex stent is easy to remove and reposition [1], and this may be an important element in its increasingly widespread use. Although the Polyflex stent is mainly inserted by endoscopists, fluoroscopic monitoring during insertion has been used with it as well - as with other stents in the gastrointestinal tract. As endoscopists often have difficulty in using fluoroscopy facilities correctly, a method of inserting this type of plastic stent with endoscopic guidance alone is described here. This method has been used three times in patients with severe and distal esophageal peptic strictures who did not respond to standard dilation procedures.

Firstly, an ultrathin gastroscope (Pentax EG-1870K) with an outer diameter of $6 \mathrm{~mm}$ is passed into the stomach. A Savary guide wire is then inserted through the working channel and left inside the gastric cavity, and the ultrathin gastroscope is withdrawn. Dilation with Savary bougies up to $12 \mathrm{~mm}$ is carried out. Next, the plastic stent, after being loaded into the applicator, is passed over the guide wire, traversing the stricture. At the distal tip of the pusher (positioner), a blue mark is made with a felt-tipped pen (Figure $\mathbf{1}$ ). This is the level at which the upper part of the stent is located. The mark is positioned several centimeters above the stricture. Release of the stent is monitored with the ultrathin endoscope in a side-toside position. The outer sheath of the applicator is gently removed at the same time as the blue mark in the pusher was kept in the desired position above the stricture, until complete deployment of the stent has been achieved (Figure $\mathbf{2}$ ).

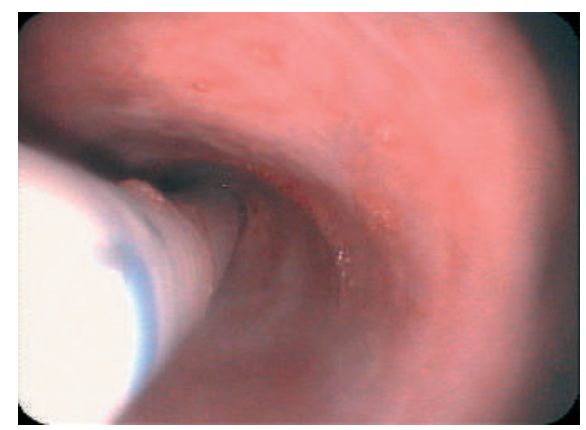

Figure 1 The Polyflex stent, loaded into the applicator, has passed the esophageal stricture and is visualized with an ultrathin gastroscope positioned alongside the applicator. A blue mark has been made on the distal tip of the pusher, corresponding to the upper level of the stent. The blue mark has to be kept several centimeters above the stricture dur-

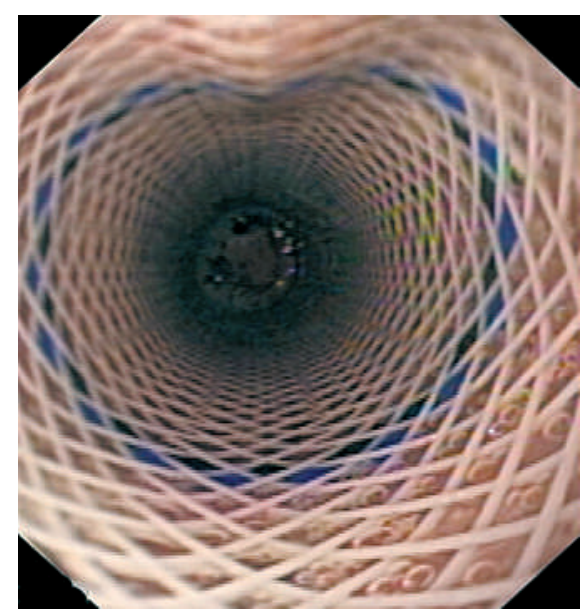

Figure 2 View of the fully deployed Polyflex stent a few days after insertion.

Petruzziello et al. described a similar method of endoscopically guided stent insertion to seal a rupture in a patient with Boerhaave's syndrome [4], although previous esophageal dilation was obviously not necessary in that case. The mark made on the pusher in the cases reported here further enhances endoscopic visualization. The manufacturer might also be able to make the already existing mark clearer in order to improve endoscopic guidance.

The insertion of self-expanding metallic stents with endoscopic guidance alone in patients with esophageal tumors has been also described [5]. However, the use of these stents in benign strictures is controversial, mainly because the stents are difficult to extract after they have been in place for several months. As stated above, however [1], the Polyflex stent has the advantage of being easily removable. Even if it has been incorrectly inserted, it can be extracted and reinserted during the same session.

\section{Endoscopy_UCTN_Code_TTT_1AO_2AZ}

\section{J. García-Cano}

Gastroenterology Service, Virgen de la Luz Hospital, Cuenca, Spain.

\section{References}

${ }^{1}$ Dormann AJ, Eisendrath P, Wigginghaus B et al. Palliation of esophageal carcinoma with a new self-expanding plastic stent. Endoscopy 2003; 35: 207-211

2 Repici A, Conio M, de Angelis C et al. Temporary placement of an expandable polyester silicone-covered stent for treatment of refractory benign esophageal strictures. Gastrointest Endosc 2004; 60: 513-519

${ }^{3}$ Gelbmann CM, Ratiu NL, Rath HC et al. Use of self-expandable plastic stents for the treatment of esophageal perforations and symptomatic anastomotic leaks. Endoscopy 2004; 36: 695-699

${ }^{4}$ Petruzziello L, Tringali A, Riccioni ME et al. Successful early treatment of Boerhaave's syndrome by endoscopic placement of a temporary self-expandable plastic stent without fluoroscopy. Gastrointest Endosc 2003; 58: $608-612$

${ }^{5}$ Austin AS, Khan Z, Cole AT, Freeman JG. Placement of esophageal self-expanding metallic stents without fluoroscopy. Gastrointest Endosc 2001; 54: 357-359

\section{Corresponding author}

\section{J. García-Cano, MD}

Gastroenterology Service

Hospital Virgen de la Luz

16002 Cuenca

Spain

Fax: +34-969-230407

Email: j.garcia-cano@terra.es

DOI: $10.1055 / s-2006-945084$ 